\title{
THE CONTROL OF NEMATOCYST DISCHARGE DURING FEEDING BY SEA ANEMONES
}

AUTHOR(S):

Mariscal, Richard N.

\section{CITATION:}

Mariscal, Richard N.. THE CONTROL OF NEMATOCYST DISCHARGE DURING FEEDING BY SEA ANEMONES. PUBLICATIONS OF THE SETO MARINE BIOLOGICAL LABORATORY 1973, 20: 695-702

ISSUE DATE:

1973-12-19

URL:

http://hdl.handle.net/2433/175750

RIGHT: 


\title{
THE CONTROL OF NEMATOCYST DISCHARGE DŨRING FEEDING BY SEA ANEMONES
}

\author{
RICHARD N. MARISCAL \\ Department of Biological Science \\ Florida State University \\ Tallahassee, Florida $\mathbf{3 2 3 0 6}$
}

With 3 Text-figures

\section{Introduction}

Nematocysts have long been considered to be independent effectors, a situation in which the nematocyst or its nematocyte acts both as a sensory receptor and effector without an intervening nervous pathway. Associated with this concept has been the idea that independent effectors generally are not under any control or influence of the organism in whose tissues they are situated, whether this control be nervous or nonnervous (e.g., see MARISCAL, 1966 and in press, for a discussion of this topic).

Although there has been considerable controversy over the years concerning the light microscopical evidence for the association of nerves with nematocysts or nematocytes, recently WeSTFALL (1970) has reported electron microscopical evidence for such an association in the hydromedusan Gonionemus. However, the whole controversy concerning direct innervation of nematocysts may be somewhat academic in that non-nervous as well as nervous conduction may be quite widespread among various coelenterates (e.g., see MACKIE, 1970). Such an epithelial or non-nervous conducting system would seem to be another obvious candidate for a possible controlling or coordinating mechanism for nematocyst discharge.

The question of whether or not such control over nematocyst discharge does in fact occur has been re-opened by various recent behavioral studies which strongly suggested this possibility (e.g., DAvenPort, Ross and Sutron, 1961; Ross and Sutton, 1964; Ellis, Ross and Sutron, 1969). These studies have indicated that a change in the pattern of tentacle nematocyst discharge can occur depending on the nature of the attachment of the pedal disc of various sea anemones. Presumably some form of information transfer is occurring between the pedal and oral disc regions which somehow affects tentacle nematocyst discharge.

Another body of literature which has suggested some form of influence over nematocyst discharge has been in the area of coelenterate feeding behavior. For example, a number of authors have reported that well-fed coelenterates often appear 
rather unresponsive and unable to capture food placed among their tentacles, while starved animals quickly capture and ingest similar food (e.g., Pantin and Pantin, 1943). Some recent workers have presented evidence that nematocyst discharge and/or prey capture seems to be reduced after heavy feeding (e.g., BurNETT, LeNTZ and Warren, 1960; BoucheT, 1961).

Observations such as these have recently prompted us to do a series of studies to investigate possible changes in the quality and quantity of nematocyst discharge during feeding by various coelenterates and to develop a reliable method for quantifying nematocyst discharge in the living, intact animal.

\section{Materials and Methods}

Two sea anemones, Calliactis tricolor Leseur from the Florida Gulf Coast and Epiactis prolifera VERRILL from the Friday Harbor region of Washington State, have been used in the studies to date.

The anemones were fed and maintained in the lab, but not fed for several days prior to an experiment. At the time of each experiment, weighed amounts of mullet were fed to Calliactis, and either scallop or live caprellids to Epiactis, the latter (Caprella laeviuscula) being the natural prey of this anemone in the Friday Harbor region. In each experiment, unfed control anemones were maintained in the same container as the experimental animals.

Nematocyst discharge was assayed using glass coverslips coated with crustacean extract; Artemia extract in the case of Calliactis and Caprella laeviuscula extract in the case of Epiactis. Coated coverslips were presented to the tentacles of both experimental and control animals at the start of the experimental series and after each feeding of the experimentals. The experimentals were fed on a different area of the oral disc than the area contacted by the coverslips and care was taken to ensure that different tentacles were contacted each time by the coverslips, to avoid depletion of the nematocyst supply. The coverslips were then dipped in a $1 \%$ solution of either methylene or toluidine blue and the number of basitrichous isorhiza nematocysts in the area contacted by the tentacles counted. Either the entire area contacted by the tentacle tip (called a "trace") or the number of nematocysts in either the 100x or $400 \mathrm{x}$ field of view were counted. However, no significant differences in the results were found between the various methods.

In order to standardize for differences in degree of contact of the tentacles with the coverslip, only the three densest areas of nematocyst deposition in each of three different traces were counted and the results averaged. Such a technique gave quite consistent and reproducible results. Control counts revealed no measurable loss of nematocysts from the coverslip, nor additional discharge of undischarged nematocysts, due to the above procedures.

For Calliactis, an index of discharge was computed in which the number of 
tentacles contacting the coverslip and leaving traces of nematocysts was also taken into consideration (e.g., see SANDBERG, KanciruK and MARISCAL, 1971). However, this proved unsatisfactory in the case of Epiactis and only the average number of discharged nematocysts from three different traces was used in calculating the results for this species.

Each anemone was fed to satiation (i.e., the point at which food was dropped from the tentacles uningested), at which time the experiment was terminated.

\section{Results}

Fig. 1 and Table 1 show the results from the experiments with Calliactis tricolor.

Table 1. Experiments with Florida Calliactis tricolor sea anemones comparing the number of nematocysts discharged to a crustacean extract-coated cover slip between experimental (fed) and control (unfed) anemones at the start and finish of the experimental series (after SANDBERG, KANCIRUK and MARISCAL, 1971).

\begin{tabular}{|c|c|c|c|c|}
\hline \multicolumn{5}{|c|}{ Index of discharge } \\
\hline \multirow[b]{2}{*}{ Experiment } & \multicolumn{2}{|c|}{ Fed anemones } & \multicolumn{2}{|c|}{ Control anemones } \\
\hline & Start & Finish & Start & Finish \\
\hline 1 & $\begin{array}{r}130 \\
90\end{array}$ & $\begin{array}{r}28 \\
0\end{array}$ & 75 & 66 \\
\hline 2 & $\begin{array}{l}115 \\
129\end{array}$ & $\begin{array}{l}5 \\
3\end{array}$ & 147 & 109 \\
\hline 3 & $\begin{array}{l}137 \\
156\end{array}$ & $\begin{array}{l}8 \\
6\end{array}$ & 136 & 122 \\
\hline 4 & $\begin{array}{l}162 \\
145\end{array}$ & $\begin{array}{l}24 \\
34\end{array}$ & 133 & 133 \\
\hline 5 & $\begin{array}{l}122 \\
163\end{array}$ & $\begin{array}{l}0 \\
3\end{array}$ & 165 & 171 \\
\hline 6 & $\begin{array}{l}127 \\
146\end{array}$ & $\begin{array}{r}10 \\
4\end{array}$ & 132 & 119 \\
\hline 7 & $\begin{array}{r}121 \\
88\end{array}$ & $\begin{array}{l}5 \\
6\end{array}$ & 125 & 127 \\
\hline 8 & $\begin{array}{l}132 \\
153\end{array}$ & $\begin{array}{l}0 \\
2\end{array}$ & 135 & 139 \\
\hline 9 & $\begin{array}{l}95 \\
80\end{array}$ & $\begin{array}{r}12 \\
5\end{array}$ & 105 & 111 \\
\hline 10 & $\begin{array}{l}76 \\
89\end{array}$ & $\begin{array}{r}2 \\
12\end{array}$ & 80 & 83 \\
\hline Range & $76-163$ & $0-34$ & $75-165$ & $66-171$ \\
\hline Mean & 118.8 & 8.4 & 123.3 & 118.0 \\
\hline $\begin{array}{l}\text { Standard } \\
\quad \text { deviation }\left(s_{\bar{x}}\right)\end{array}$ & 9.52 & 2.13 & 9.01 & 9.20 \\
\hline$t$ value & (h & y significant) & & $\begin{array}{l}.82 \\
\text { ignificant) }\end{array}$ \\
\hline
\end{tabular}

Twenty anemones were used; three per experiment--two experimentals, and one control. The time for each experiment varied from 60-153 $\mathrm{min}$ (average $109 \mathrm{~min}$ ). The number of pieces (about $0.1 \mathrm{~g}$ each) needed for satiation ranged from $7-29$ (average 16). 
It will be noted that with increased feeding there is a sharp decrease in the number of nematocysts discharged. At satiation, nematocyst discharge to the same food stimulus that had originally caused a heavy nematocyst discharge, was extremely slight. Although the different experimental anemones varied somewhat in weight, calculations based on the per cent of the anemone's body weight of food ingested gave similar curves (Figs. 1, 2, 3). In all cases, there was an initial sharp decrease in the number of nematocysts discharged, but following the second or third feeding, the slope of the curve began leveling off, more or less remaining at this level until satiation. Within 30 minutes after egestion of the food bolus, the numbers of nematocysts discharged returned to the prefeeding level.

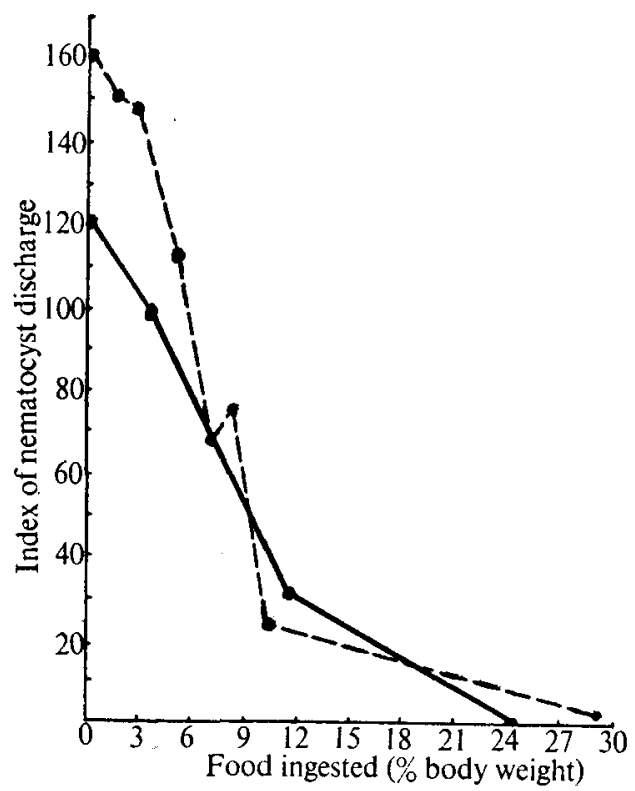

Fig. 1. Experiments with Florida Calliactis tricolor sea anemones showing a decrease in nematocyst discharge with increase in the amount of food ingested (plotted as per cent anemone's body weight). Solid line represents data for a 3.28 gram anemone and the dashed line represents data for a 6.84 gram anemone. (after SANDbERg, Kanciruk and MARISCAL, 1971).

In the case of the unfed controls, nematocyst discharge remained at the high initial level throughout the experiments (Table 1).

Both "natural" and "unnatural" food was fed to the Epiactis anemones. The unnatural food consisted of pieces of the adductor muscle of the scallop, Chlamys hericius (Fig. 2). The results of experiments using this food source were the same as those in which pieces of mullet were fed to Calliactis.

However, in order to see if a natural food gave similar results, weighed quantities 


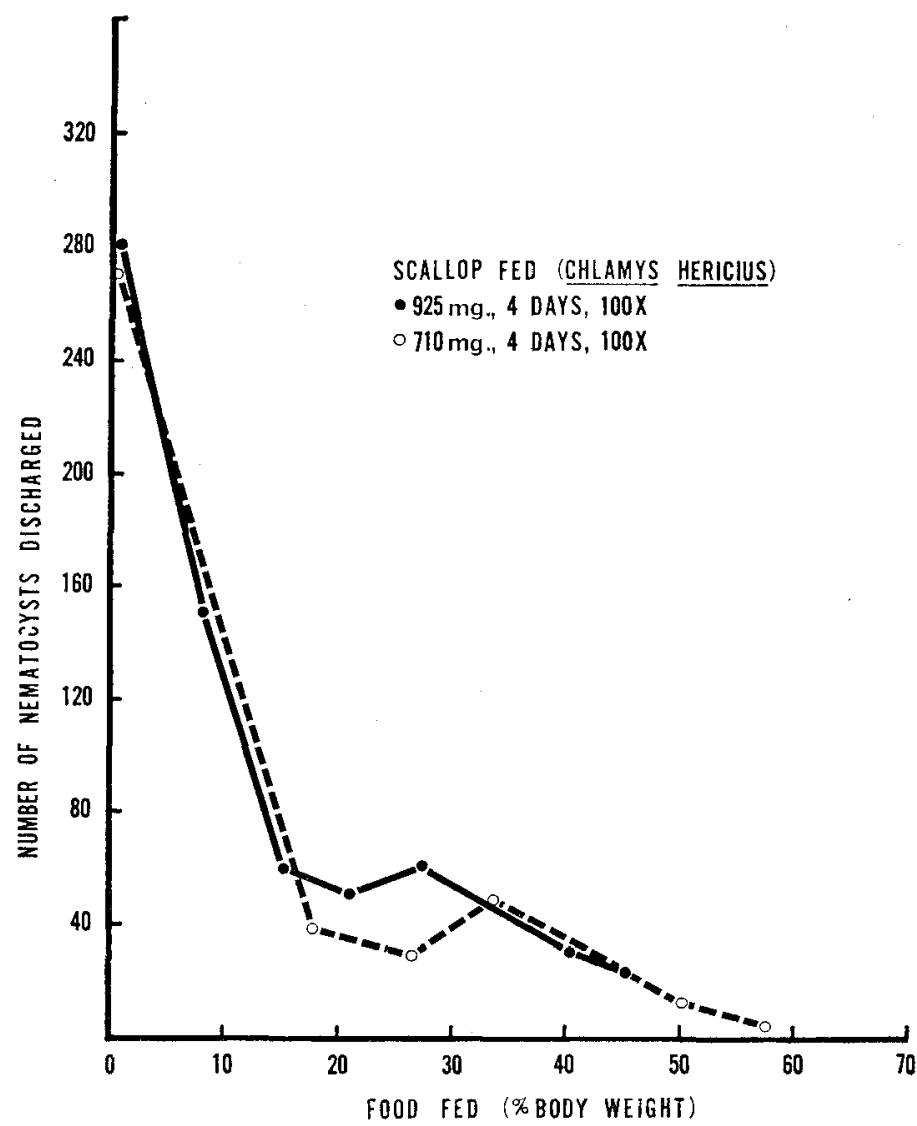

Fig. 2. Experiments with Washington Epiactis prolifera sea anemones showing a decrease in nematocyst discharge with an increase in feeding of scallop (Chlamys hericius) adductor muscle (plotted as per cent anemone's body weight). Solid line represents data for a $925 \mathrm{mg}$. anemone starved for four days prior to the start of the experiments. Dashed line represents data for a $710 \mathrm{mg}$. anemone starved for four days prior to the start of the experiments. The nematocysts of both anemones were counted at $100 \mathrm{x}$.

of the caprellid, Caprella laeviuscula, were also presented to Epiactis. This caprellid was found in large numbers on the Zostera blades to which Epiactis was commonly attached and was also observed being both ingested and egested by the anemone. Figure 3 shows the results of these experiments.

It will be noted in all experiments that the number of nematocysts discharged to the coverslips always started off at a fairly high level and then dropped rapidly after only a few feedings. The weight of the anemones, the length of starvation time and the method of counting, whether it be the whole trace, or the nematocysts in the $100 \mathrm{x}$ or $400 \mathrm{x}$ fields of view, did not significantly affect the results. 


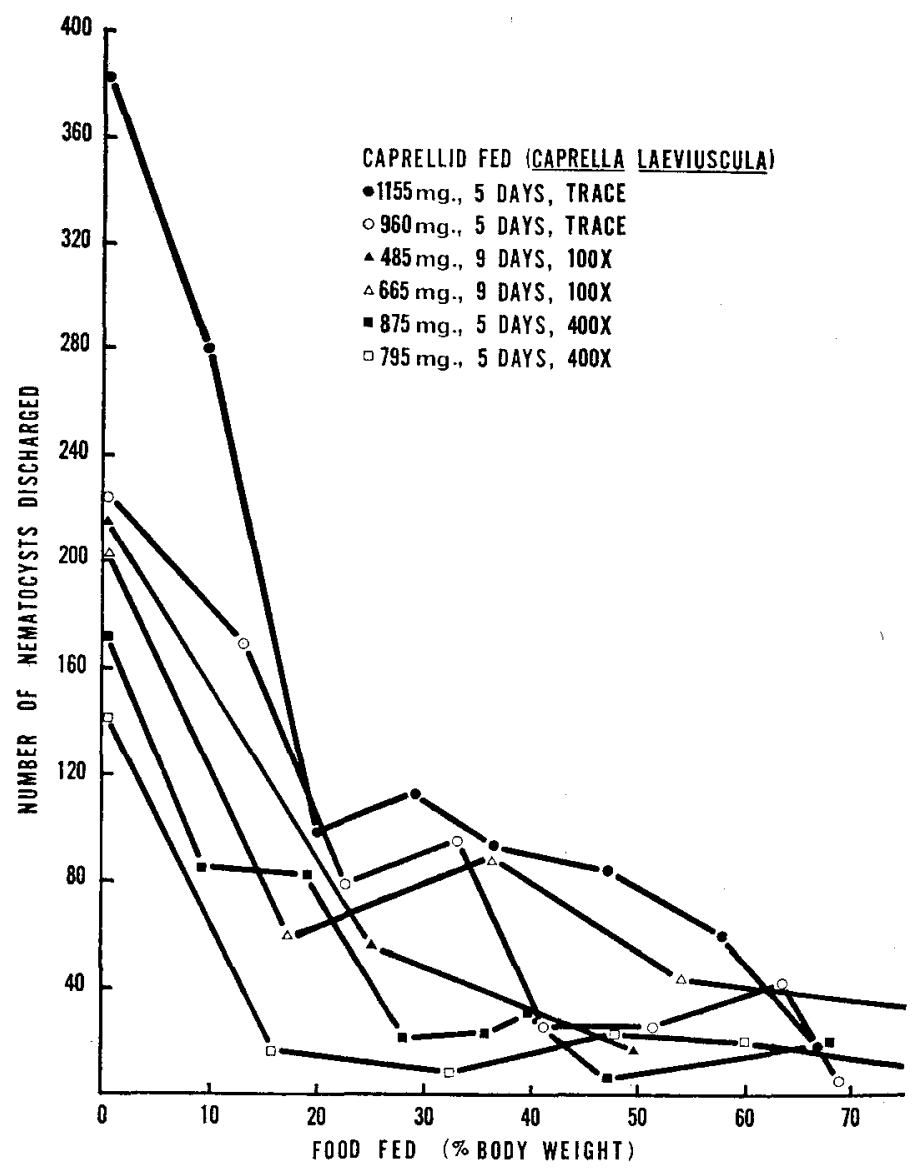

Fig. 3. Experiments with Washington Epiactis prolifera sea anemones showing a decrease in nematocyst discharge with an increase in feeding of live caprellids (Caprella laeviuscula), plotted as per cent anemone's body weight. The anemone's body weight, number of days starved before the experiments and the method of counting (i.e., the whole tentacle trace, or the number of nematocysts in the $100 \mathrm{x}$ or $400 \mathrm{x}$ fields of view) are shown on the graph.

\section{Discussion}

It seems clear that the ability of a coelenterate to "turn off" its nematocyst discharge after feeding is adaptive and of benefit to both the individual and the species. In this way, a coelenterate is able to prevent "wasting" its supply of nematocysts to capture food that it is unable to ingest or otherwise utilize. Since nematocysts are probably the largest and structurally the most complex intracellular secretion product of any animal known, any means of conserving this limited supply would presumably be metabolically advantageous to the species. Although perhaps it is a bit premature 
to speak of the "control" of nematocyst discharge, it does seem clear that some coelenterate nematocysts, at least, may be under the influence of the animal to a surprisingly marked degree.

The nature of the controlling mechanism and whether it is nervous or non-nervous remain to be investigated. Studies along this line, as well as additional studies in such groups as the colonial hydrozoans and the scyphozoans, are needed to determine if their nematocysts are also under some form of control by the animal itself.

In addition, it is time that the whole concept of independent effectors, at least in the case of coelenterate nematocysts, be reinvestigated. Many of the current ideas regarding the independent effector concept seem to have been strongly influenced by the opinions of G. H. PARKer (1919) as expressed in his book, "The Elementary Nervous System". LenTz (1968) points out that "The essential factor in PARKeR's definition of independent effectors is the capacity of the effector to be stimulated directly". Bullock and Horridge (1965) define independent effectors as "cells specialized as effectors which do not require receptor or nerve cells to initiate their actions". The recent studies on coelenterates suggest that the influence of the animal over nematocyst discharge may be more inhibitory than stimulatory, although there are indications that the latter situation also occurs (e.g., the apparent strong increase in the intensity of tentacle nematocyst discharge by some sea anemones when attempts are made to pry the pedal disc free of the substrate).

In any case, it would seem that the time is ripe for a reinvestigation of this problem and it is hoped that further studies will be directed toward not only working out the pathways of control of nematocyst discharge, but also in clarifying the question of whether or not nematocysts are, in fact, independent effectors.

\section{Acknowledgements}

A portion of the work on Calliactis described here has been published elsewhere (SANDBERG, KANCIRUK and MarisCal, 1971) and thanks are due Nature for permission to reproduce Fig. 1 and Table 1. The use of facilities at the Friday Harbor Laboratories of the University of Washington and the Bodega Marine Laboratory of the University of California is also greatly appreciated.

\section{REFERENCES}

Bouchet, C. 1961. Le Contrôle de la décharge nématocystique chez 1'Hydre. C. R. Acad. SC., 252: $327-328$.

Bullock, T. H. and Horridge, G. A. 1965. "Structure and Function in the Nervous Systems of Invertebrates." Vol. I. San Francisco: W. H. Freeman and Co.

Burnett, A. L., Lentz, T. and Warren, M. 1960. The nematocyst of Hydra. (Part I). The question of control of the nematocyst discharge reaction by fully fed hydra. Ann. Soc. Roy. Zool. Belg., 90: 247-267.

DAVEnPort, D., Ross, D. M. and Sutton, L. 1961. The remote control of nematocyst-discharge in the attachment of Calliactis parasitica to shells of hermit crabs. Vie et Milieu, 12 (2): 197-209.

Ellis, V. L., Ross, D. M. and Sutton, L. 1969. The pedal disc of the swimming sea anemone 
Stomphia coccinea during detachment, swimming, and resettlement. Canad. J. Zool., 47 (3): 333-342.

Lentz, T. L. 1968. " "Primitive Nervous Systems." New Haven: Yale Univ. Press.

MACKIE, G. O. 1970. Neuroid conduction and the evolution of conducting tissues. Quart. Rev. Biol., 45 (4): 319-332.

MARISCAL, R. N. 1966. The symbiosis between tropical sea anemones and fishes: a review. In R. I. Bowman (ed.), "The Galápagos," pp. 157-171. Berkeley: Univ. Calif. Press.

Mariscal, R. N. (in press). Nematocysts. In H. M. Lenhoff and L. Muscatine (eds.), "Recent Perspectives in the Biology of Coelenterates." New York: Academic Press.

Pantin, C. F. A. and Pantin, A. M. P. 1943. The stimulus to feeding in Anemonia sulcata. J. Exp. Biol., 20 (1): 6-13.

Parker, G. H. 1919. "The Elementary Nervous System." Philadelphia: Lippincott.

Ross, D. M. and SutTon, L. 1964. Inhibition of the swimming response by food and of nematocyst discharge during swimming in the sea anemone Stomphia coccinea. J. Exp. Biol. 41 (4): 751-757.

SANDBerG, D. M., KANCIRUK, P. and MARISCAL, R. N. 1971. Inhibition of nematocyst discharge correlated with feeding in a sea anemone, Calliactis tricolor (Leseur). Nature, 232: 263-264.

Westrall, J. A. 1970 . The nematocyte complex in a hydromedusan, Gonionemus vertens. $Z$. $f$. Zellforsch., 110 (3): 347-470. 